\title{
Recent Advances in Carbon-Nanotube-Based Epoxy Composites
}

\author{
Fan-Long Jin ${ }^{1, \AA}$ and Soo-Jin Park ${ }^{2, \star s}$ \\ ${ }^{1}$ School of Chemical and Materials Engineering, Jilin Institute of Chemical Technology, Jilin City 132022, China \\ ${ }^{2}$ Department of Chemistry, Inha University, Incheon 402-751, Korea
}

\section{Article Info}

Received 4 September 2012

Accepted 30 October 2012

*Corresponding Author

E-mail: jinfanlong@gmail.com sjpark@inha.ac.kr

\section{Open Access}

DOI: http://dx.doi.org/

10.5714/CL.2012.14.1.001

This is an Open Access article distributed under the terms of the Creative Commons Attribution Non-Commercial License (http://creativecommons.org/licenses/ by-nc/3.0/) which permits unrestricted non-commercial use, distribution, and reproduction in any medium, provided the original work is properly cited.

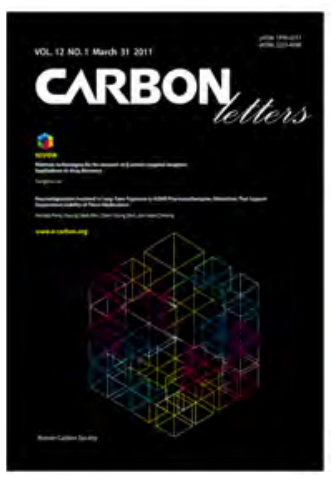

http://carbonlett.org

pISSN: $1976-4251$

elSSN: 2233-4998

Copyright $\odot$ Korean Carbon Society

\begin{abstract}
Carbon nanotubes (CNTs) are increasingly attracting scientific and industrial interest because of their outstanding characteristics, such as a high Young's modulus and tensile strength, low density, and excellent electrical and thermal properties. The incorporation of CNTs into polymer matrices greatly improves the electrical, thermal, and mechanical properties of the materials. Surface modification of CNTs can improve their processibility and dispersion within the composites. This paper aims to review the surface modification of CNTs, processing technologies, and mechanical and electrical properties of CNT-based epoxy composites.
\end{abstract}

Key words: carbon nanotubes, surface modification, electrical properties, composites, mechanical properties

\section{Introduction}

Epoxy resins are widely used in practical applications, such as coatings, electronics, adhesives, and as matrices for composites because of their excellent mechanical properties, high adhesiveness to many substrates, and good heat and chemical resistances. However, the materials are inherently brittle as a result of their high crosslinking density, which puts a constraint on many engineering applications. Many attempts have been made to improve their physical properties using liquid elastomers, thermoplastics, and inorganic particles [1-4].

Recently, epoxy composites containing carbon nanotubes (CNTs) have received a tremendous amount of attention. CNTs can be constructed with length-to-diameter ratios that are significantly higher than those of any other materials, providing them with extraordinary mechanical, electronic, and thermal properties $[5,6]$. Thus, CNTs have tremendous potential in many scientific and technological applications. In particular, they would be useful as a filler in epoxy composites for improving the performance of the resulting composites [7-9].

However, the low solubility and weak dispersibility of CNTs in common solvents and epoxy matrices have limited their application in this area. Methods that have proven effective for improving the dispersion of CNTs can be divided into the categories of mechanical, physical, and chemical. Ultrasonic dispersing and high-shear mixing are examples of commonly used mechanical methods. Physical methods involve the adsorption and/or wrapping of polymers or surfactants to the surface of the CNTs, and chemical methods consist of covalent chemical bonding (grafting) of polymer chains to the CNT surfaces, which dramatically improves interfacial interactions between them and the epoxy matrix [10-15].

In this paper, the surface modification of CNTs and methods used to process them are reviewed in detail. In addition, the mechanical and electrical properties of CNT-based epoxy composites are discussed. 


\section{Surface Modification of CNTs}

It is difficult to disperse pristine CNTs (P-CNTs) in a polar epoxy matrix because of their large surface area and strong intrinsic van der Waals forces, which cause them to aggregate. The dispersion of CNTs in epoxy resins is one of the most important challenges that needs to be overcome in order to fully realize their potential in epoxy-based CNT composites. Therefore, development of processing techniques that effectively reduce the aggregation of nanotubes within an epoxy resin is vital $[16,17]$.

Many different chemical modification techniques have been studied for enhancing interfacial adhesion between CNTs and an epoxy matrix. Both covalent and non-covalent methods have been investigated for functionalizing the CNT surfaces. Covalent surface modification involves the formation of a chemical linkage between the polymer chains of the epoxy resins and functional groups on the surface of the CNTs. Non-covalent functionalization methods, which include solution mixing, melt mixing, and in situ polymerization, enable the conjugated structure of CNT sidewalls to be retained: however, the interfacial interaction between the nanotubes and the epoxy matrix are generally poor. For both of these approaches, it is necessary that the sidewalls be modified without significantly altering the desirable properties of the CNTs [18-21].

Acid oxidation is a well-known method for introducing reactive oxygen-containing moieties, such as carboxyl, carbonyl, and hydroxyl groups, onto CNT surfaces. This method uses strong acids such as $\mathrm{HNO}_{3}$ and $\mathrm{H}_{2} \mathrm{SO}_{4}$. Oxidized CNTs have demonstrated improved dispersion and interfacial behavior within various polymer matrices [22,23].

Sidewall functionalization of CNTs with organic chains or functional groups is another effective way to improve the dispersion and reinforce the combination of CNTs with the epoxy matrix. Reactive oxygen-containing moieties produced by acid oxidation can be further transformed into other functional groups using acryl chloridization, amination, esterification, and a variety of other methods $[24,25]$.

Attachment of functional groups and polymer chains to CNTs cannot only improve dispersion of CNTs in the epoxy matrix but also enhance the binding strength at the polymer-CNT interface. Coupling between CNTs and the polymer matrix is also extremely important for efficient transfer of external stress to the nanotube structures $[26,27]$.

\subsection{Oxidation of CNTs (O-CNTs)}

2.1.1. Oxidation by a mixture of $\mathrm{H}_{2} \mathrm{SO}_{4} / \mathrm{HNO}_{3}$

A general procedure for oxidizing P-CNTs using a mixture of $\mathrm{H}_{2} \mathrm{SO}_{4} / \mathrm{HNO}_{3}$ is as follows. P-CNTs are placed in an oven at $100^{\circ} \mathrm{C}$ for $2 \mathrm{~h}$. The oxidation of CNTs is carried out in a threenecked round-bottomed flask equipped with a reflux condenser, mechanical stirrer, and thermometer. P-CNTs $(0.2 \mathrm{~g})$ are immersed in a mixture of concentrated $\mathrm{H}_{2} \mathrm{SO}_{4} / \mathrm{HNO}_{3}(3: 1 \mathrm{v} / \mathrm{v})$ to remove impurities from the surface of the nanotubes. The mixture is then sonicated in a water bath at $40^{\circ} \mathrm{C}$ for $1-3 \mathrm{~h}$, filtered, and the remaining solid is washed by repeated rinsing with deionized water until the $\mathrm{pH}$ reached 6-7. Finally, the acid-treated CNTs are dried at $100^{\circ} \mathrm{C}$ for $24 \mathrm{~h}$ in a vacuum oven. This proce-
Table 1. Elemental composition of CNTs before and after acid

treatment [17]

\begin{tabular}{ccccc} 
Element (atomic \%) & $\mathrm{C}$ & $\mathrm{O}$ & $\mathrm{N}$ & $\mathrm{O} / \mathrm{C}(\%)$ \\
\hline P-CNTs & 94.8 & 1.5 & 0 & 1.6 \\
O-CNTs & 92.0 & 5.1 & 0 & 5.5
\end{tabular}

P-CNTs: pristine carbon nanotubes, O-CNTs: oxidized CNTs.

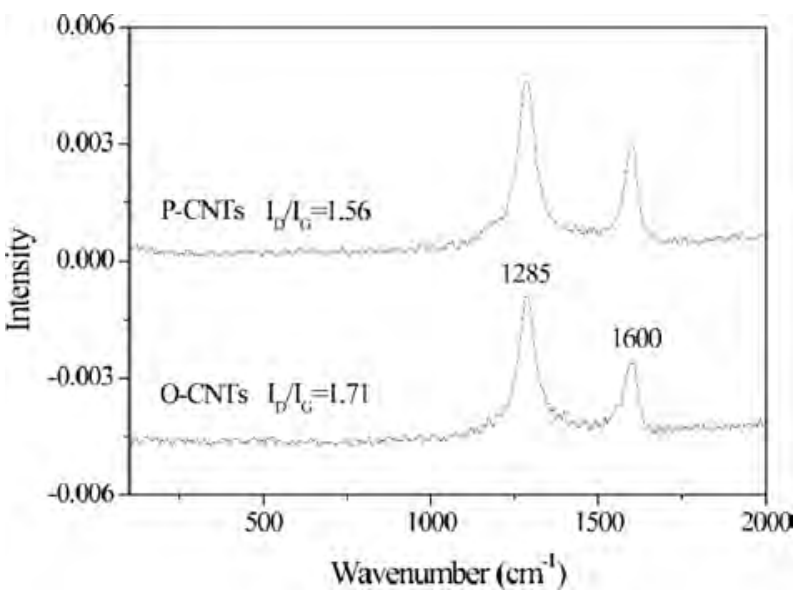

Fig. 1. Raman spectra of CNTs before and after acid oxidation [17]. PCNTs: pristine carbon nanotubes, O-CNTs: oxidized CNTs.

dure results in the formation of carboxyl groups on the surface of the CNTs (abbreviated as O-CNTs) [17,28].

Jin et al. [17] demonstrated the oxidation of P-CNTs with a 3:1 mixture of concentrated $\mathrm{H}_{2} \mathrm{SO}_{4}$ and $\mathrm{HNO}_{3}$ by stirring at $40^{\circ} \mathrm{C}$ for $4 \mathrm{~h}$. Table 1 shows the elemental composition of CNTs before and after acid treatment. The $\mathrm{O} / \mathrm{C}$ ratios of P-CNTs and $\mathrm{O}-\mathrm{CNTs}$ samples were $1.6 \%$ and $5.5 \%$, respectively, which confirmed the effectiveness of the acid treatment process in generating carboxyl groups on the CNT surfaces. They used Raman spectroscopy probe the structural alterations of the CNTs, and their results are shown in Fig. 1. The intensity ratio of the $\mathrm{D}$ and $\mathrm{G}$ bands $\left(\mathrm{I}_{\mathrm{D}} / \mathrm{I}_{\mathrm{G}}\right)$ of the CNTs increased from 1.56 to 1.71 with acid treatment, as a result of the formation of $\mathrm{sp}^{3}$-hybridized carbon defect sites that resulted from the creation of functional groups. Similar results were observed by Hsu et al. [16] and Hadjiev et al. [28] using multi-walled CNTs (MWCNTs).

2.1.2. Oxidation by a mixture of $\mathrm{H}_{2} \mathrm{SO}_{4} / \mathrm{H}_{2} \mathrm{O}_{2}$

A general procedure for oxidizing P-CNTs using a mixture of $\mathrm{H}_{2} \mathrm{SO}_{4} / \mathrm{H}_{2} \mathrm{O}_{2}$ is as follows. P-CNTs are oxidized by a mixture of $\mathrm{H}_{2} \mathrm{SO}_{4} / \mathrm{H}_{2} \mathrm{O}_{2}(3: 1 \mathrm{v} / \mathrm{v})$ in a round-bottomed flask at $40^{\circ} \mathrm{C}$ for $4 \mathrm{~h}$. The resulting dispersion is diluted in deionized water to remove the residual acid and then filtered. O-CNTs are then obtained after drying in a vacuum at $60^{\circ} \mathrm{C}$ for $12 \mathrm{~h} \mathrm{[29].}$

Luo et al. [29] studied the oxidation of P-MWCNTs using a mixture of $\mathrm{H}_{2} \mathrm{SO}_{4} / \mathrm{H}_{2} \mathrm{O}_{2}$. Their Raman spectroscopy results indicated that the $I_{\mathrm{D}} / I_{\mathrm{G}}$ of O-MWCNTs (1.543) was higher than that of P-MWCNTs (1.244), which was the result of some of the $\mathrm{sp}^{2}$ carbon atoms being converted to $\mathrm{sp}^{3}$ carbon atoms on the surface of the MWCNTs as carboxyl groups were formed by the acid treatment. 
Table 2. Raman spectroscopy of untreated and treated MWCNTs [30]

\begin{tabular}{|c|c|c|c|}
\hline \multirow{2}{*}{ Treatment method } & \multicolumn{2}{|c|}{ Raman shift $\left(\mathrm{cm}^{-1}\right)$} & \multirow{2}{*}{$\begin{array}{c}\mathrm{I}_{\mathrm{D}} / \mathrm{I}_{\mathrm{G}} \text { intensity } \\
\text { ratio }\end{array}$} \\
\hline & $\mathrm{D}$ & G & \\
\hline Untreated & 1340 & 1581 & 1.42 \\
\hline $5 \mathrm{M} \mathrm{HNO}_{3}$ treated & 1344 & 1578 & 1.50 \\
\hline $16 \mathrm{M} \mathrm{HNO}_{3}$ treated & 1340 & 1578 & 1.54 \\
\hline $\begin{array}{c}\left(3 \mathrm{M} \mathrm{HNO}_{3}+4 \mathrm{M} \mathrm{HCl}\right) \\
\text { treated }\end{array}$ & 1344 & 1582 & 1.52 \\
\hline $\begin{array}{c}\left(16 \mathrm{M} \mathrm{HNO}_{3}+18 \mathrm{M} \mathrm{H}_{2} \mathrm{SO}_{4}\right) \\
\text { treated }\end{array}$ & 1348 & 1583 & 1.55 \\
\hline
\end{tabular}

MWCNTs: multi-walled carbon nanotubes.

\subsubsection{Oxidation by $\mathrm{HNO}_{3}$}

A general procedure for oxidizing P-CNTs using $\mathrm{HNO}_{3}$ is as follows. Dried P-CNTs are stirred into a $\mathrm{HNO}_{3}$ solution (1:3 $\mathrm{w} / \mathrm{w})$ and the mixture is boiled at $100^{\circ} \mathrm{C}$ for $1-2 \mathrm{~h}$ with stirring at $300 \mathrm{rpm}$. To eliminate the $\mathrm{HNO}_{3}$, the mixture is washed repeatedly with deionized water until the $\mathrm{pH}$ approaches 6-7, and then the modified CNTs are dried in an oven at $100^{\circ} \mathrm{C}$ [30].

Kim et al. [30] demonstrated the oxidation of MWCNTs using $\mathrm{HNO}_{3}$. The Raman shift values and the $I_{\mathrm{D}} / I_{\mathrm{G}}$ intensity ratios are presented in Table 2. The $I_{\mathrm{D}} / I_{\mathrm{G}}$ values of the O-MWCNTs clearly exceeded those of the P-MWCNTs because of presence of carbon defect sites on the MWCNT walls.

\subsection{4. $\mathrm{UV} / \mathrm{O}_{3}$-treated $\mathrm{CNTs}\left(\mathrm{UV} / \mathrm{O}_{3}-\mathrm{CNTs}\right)$}

A general procedure for oxidizing P-CNTs using $\mathrm{O}_{3}$ is as follows. P-CNTs $(1 \mathrm{~g})$ are placed in a homemade vertical reactor. $\mathrm{O}_{3}\left(5 \mathrm{wt} \%\right.$ in $\left.\mathrm{O}_{2}\right)$ is continuously passed through the reaction chamber at room temperature during the oxidation process. The gas flow rate and humidity inside the reactor are kept at $150 \mathrm{~L} / \mathrm{h}$ and $2 \%$, respectively, and the reaction time varies from 0.5 to 6 h. For $\mathrm{H}_{2} \mathrm{O}$-assisted ozonolysis, $\mathrm{H}_{2} \mathrm{O}$ and $\mathrm{O}_{3}$ are introduced into the reaction chamber simultaneously. The humidity in the chamber and the flow rate of the mixture are kept at approximately $60 \%$ and $150 \mathrm{~L} / \mathrm{h}$, respectively [31].

Peng et al. [31] described a method for CNT oxidation at room temperature using $\mathrm{O}_{3}$ with added $\mathrm{H}_{2} \mathrm{O}$ vapor. The resulting CNTs were characterized using Fourier-transform infrared spectroscopy (FT-IR), X-ray photoelectron spectroscopy (XPS), scanning electron microscope spectroscopy (SEM), and transmission electron microscopy (TEM). As shown in Table 3, the $\mathrm{O} / \mathrm{C}$ atom ratio obtained from the XPS increased from 0.01 (P-MWCNTs) to 0.07 for O-MWCNTs and 0.14 for $\mathrm{H}_{2} \mathrm{O}-\mathrm{O}$ -
MWCNTs. In the presence of $\mathrm{H}_{2} \mathrm{O}$ vapor, the $\mathrm{O}_{3}$ oxidant might partially decompose to generate hydroxyl radicals. TEM imaging revealed damaged graphite sheets as well as formed amorphous carbon entities, implying that the ozonization initiated at the outer layer and subsequently progressed to the inner layer of the MWCNTs.

\subsection{Chemical treatment of CNTs}

Enhancement of the interaction of CNTs with an epoxy matrix can be achieved by covalent attachment of functional groups to the nanotube walls that can react directly with the epoxy chains. The key issue in obtaining a successful covalent functionalization is the selection of the correct organic molecule, which provides both efficient grafting to the CNT surface and reactivity towards the epoxy matrix. The construction of a CNT-epoxy matrix covalent bond constitutes the strongest type of interfacial interaction and is superior to physical interactions such as van der Waals forces $[17,22,29,32]$.

\subsubsection{Amine functionalization of CNTs (amino-CNTs)}

Amino-CNTs have been developed in recent years for improving the dispersion and interfacial adhesion of CNTs within epoxy resins. The amino-CNTs were obtained by direct coupling between an organic amine and carboxylic acid groups previously formed on the CNT surface. In a typical procedure, 50 $\mathrm{mg}$ of O-CNTs were dispersed in $50 \mathrm{~mL}$ of toluene, using ultrasonication in a water bath for $60 \mathrm{~min}$. Subsequently, $5 \mathrm{~mL}$ of a $10 \mathrm{wt} \%$ solution of ethylenediamine in toluene, $800 \mathrm{mg}$ of dicyclohexylcarbodiimide, and $100 \mathrm{mg}$ of dimethylaminopyridine were sequently added, and the mixture was stirred magnetically at $60^{\circ} \mathrm{C}$ for $2 \mathrm{~h}$. After the reaction, $50 \mathrm{~mL}$ of ethanol was added in order to dilute the unreacted ethylenediamine and the catalytic molecules. Amino-CNTs were obtained by filtration and washing with ethanol and water, three times each. The product was dried in a vacuum at $60^{\circ} \mathrm{C}$ for $4 \mathrm{~h}$ [22].

$\mathrm{Ma}$ et al. [22] studied the amino-functionalization of $\mathrm{UV} / \mathrm{O}_{3}$ treated CNTs. Surface functionalization was confirmed by FTIR and XPS. The results of static contact angle measurements indicated that the amino-CNTs contained both amine and amide groups on the surface, resulting in enhanced hydrophilicity, and therfore adhesivity, to the epoxy resin, as shown in Table 4.

Jin et al. [17] prepared dodecylamine-functionalized CNTs (amino-CNTs). As shown in Fig. 2, in the thermogrametric analysis (TGA) the temperature of $5 \%$ weight loss of P-CNTs was $735^{\circ} \mathrm{C}$. The weight loss of the amino-CNT sample at this temperature was significantly higher, at $15.2 \%$, which was mainly attributed to the decomposition of dodecyl groups. TEM images demonstrated that the outer shell of the amino-CNTs was cov-

\section{Table 3. Chemical composition of the functional groups on surface of P-MWCNTs, O-MWCNTs and $\mathrm{H}_{2} \mathrm{O}-\mathrm{A}-\mathrm{MWCNTs}$ [31]}

\begin{tabular}{ccccccc} 
Sample & $\mathrm{O} / \mathrm{C}$ & $\mathrm{C}=\mathrm{C} \%(284.6 \mathrm{eV})$ & $\mathrm{C}-\mathrm{O} \%(285.6 \mathrm{eV})$ & $\mathrm{C}=\mathrm{O} \%(287 \mathrm{eV})$ & $\mathrm{O}=\mathrm{C}-\mathrm{O} \%(289.5 \mathrm{eV})$ & $\square-\square * \%(291 \mathrm{eV})$ \\
\hline p-MWCNTs & 0.01 & 65 & 8 & 12 & - & 15 \\
O-MWCNTs & 0.07 & 55 & 16 & 14 & 15 & - \\
$\mathrm{H}_{2}$ O-O-MWCNTs & 0.14 & 45 & 15 & 16 & 24 & -
\end{tabular}

P-MWCNTs: pristine multi-walled carbon nanotubes, O-MWCNTs: oxidized multi-walled CNTs, $\mathrm{H}_{2} \mathrm{O}-\mathrm{O}-\mathrm{MWCNTs}$ : $\mathrm{H}_{2} \mathrm{O}-\mathrm{O}_{3}$ treated multi-walled CNTs. 
Table 4. Contact angles of various droplets on CNT substrate [22]

\begin{tabular}{cccc} 
CNTs & Water $\left({ }^{\circ}\right)$ & $\begin{array}{c}\text { Ethylene } \\
\text { glycol }\left({ }^{\circ}\right)\end{array}$ & DGEBA $\left({ }^{\circ}\right)$ \\
\hline P-CNTs & $72.0 \pm 3.1$ & $31.8 \pm 2.4$ & $74.1 \pm 2.6$ \\
Amino-CNTs & $43.0 \pm 2.1$ & $21.8 \pm 3.7$ & $61.5 \pm 3.2$ \\
\hline
\end{tabular}

P-CNTs: pristine carbon nanotubes, amino-CNTs: amine functionalized CNTs, DGEBA: diglycidyl ether of bisphenol A.

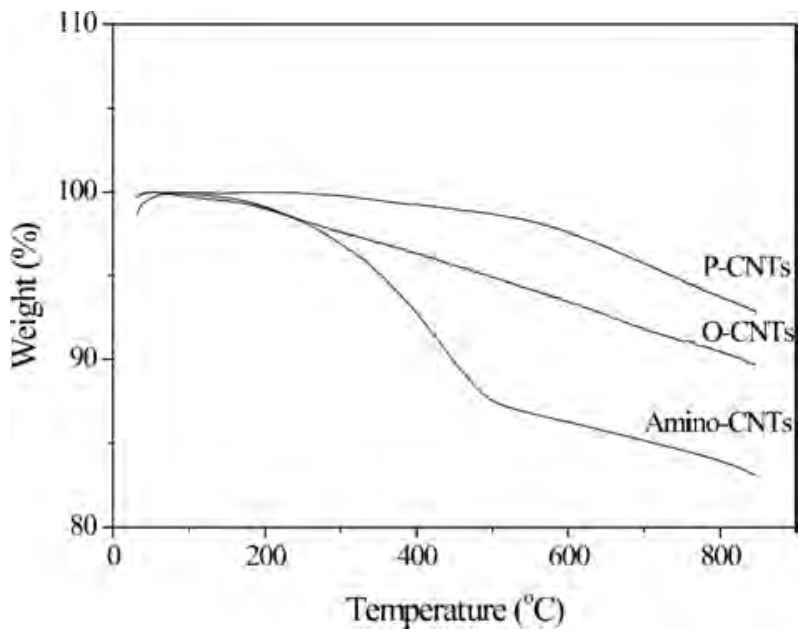

Fig. 2. Thermogrametric analysis thermograms of CNT samples [17] P-CNTs: pristine carbon nanotube, O-CNTs: oxidized CNTs, amino-CNTs: dodecylamine-functionalized CNTs.

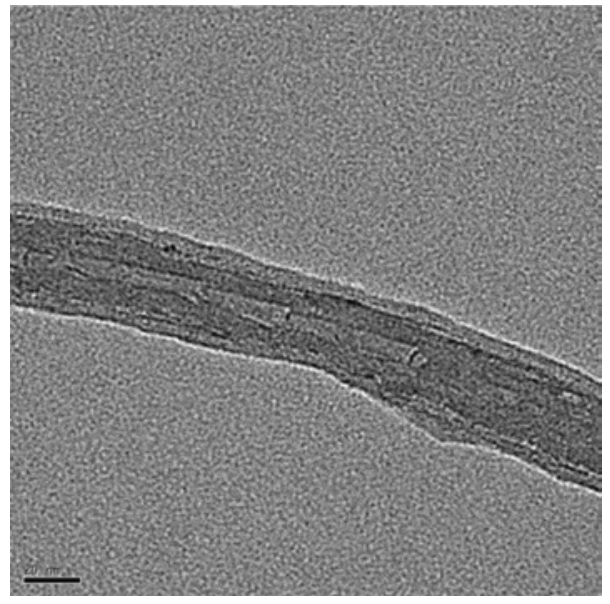

Fig. 3. Transmission electron microscopy image of amino-CNTs [17]. amino-CNTs: dodecylamine functionalized carbon nanotubes.

ered with a thin layer of amorphous material, as shown in Fig. 3.

Yaping et al. [32] studied the effect of functionalization on epoxy/CNT nanocomposites. TEM results showed that aminoCNTs were efficiently dispersed in the nanometric-class microfibers in the epoxy matrix. The diameter of the amino-CNTs ranged from 20 to $30 \mathrm{~nm}$, and the length reached several hundred microns. The amino-CNTs were evenly distributed in the epoxy resin, ensuring a greater interfacial strength, which is beneficial for improving the properties of the epoxy resin.
Table 5. Dispersive surface energies $\left(\gamma_{s}^{D}\right)$ and specific free energies $\left(\Delta \mathrm{G}_{\mathrm{sp}}\right)$ of different MWCNTs [29]

\begin{tabular}{cccc} 
Sample & $\gamma_{\mathrm{S}}{ }^{\mathrm{D}}\left(\mathrm{mJ} / \mathrm{m}^{2}\right)$ & $\begin{array}{c}\Delta G_{\text {sp }} \text { in ac- } \\
\text { etone }(\mathrm{kJ} / \mathrm{mol})\end{array}$ & $\begin{array}{c}\Delta G_{\text {sp }} \text { in etha- } \\
\mathrm{nol}(\mathrm{kJ} / \mathrm{mol})\end{array}$ \\
\hline P-MWCNTs & 122.95 & 10.74 & 9.41 \\
$\begin{array}{c}\text { Dicyanodi- } \\
\text { amide-function- } \\
\text { alized MWCNTs }\end{array}$ & 18.65 & 1.14 & 0.53 \\
$\begin{array}{c}\text { Phenylbigua- } \\
\text { nide-functional- } \\
\text { ized MWCNTs }\end{array}$ & 25.69 & 2.84 & 3.96 \\
\hline
\end{tabular}

P-MWCNTs: pristine multi-walled carbon nanotubes.

Luo et al. [29] investigated the effect of amino-functionalization on the interfacial adhesion of epoxy/CNT nanocomposites. As shown in Table 5, the grafting of amino-organics onto the surface of MWCNTs resulted in a reduction in dispersive surface energy, $\gamma_{\mathrm{s}}{ }^{\mathrm{D}}$. The specific free energies, $\Delta G_{\mathrm{sp}}$, of the functionalized MWCNTs were significantly decreased, reflecting the reduced interaction between functionalized MWCNTs and polar probe molecules.

Armstrong et al. [33] investigated improved performance of epoxy nanocomposites containing amine-functionalized CNTs. SEM images showed worm-like structures, and the nanotubes were thicker and appeared inflated. The images also showed a Y-junction where two CNTs were connected. The junctions, as well as the inflation of the amino-CNTs, would be expected to affect the properties of the final epoxy/CNT composites.

Yang and $\mathrm{Gu}$ [34] studied the effects of grafting triethylenetetramine to CNTs on the dispersion, the filler-matrix interfacial interactions, and the thermal properties of the epoxy nanocomposites. TEM images demonstrated the appearance of an extra phase on the MWCNT wall after chemical modification, indicating that the grafting reactions had successfully occurred. SEM images showed that the triethylenetetramine grafting could break up large agglomerations and produce individual MWCNTs.

\subsubsection{Silane modification of CNTs}

The silanization of CNTs is another method that has been used to enhance the interfacial adhesion between nanotubes and the matrix. The silane coupling agents most commonly used are organosilanes, which readily react with hydroxyl groups produced on the CNT surface using oxidation and/or reduction processes.

A general procedure for silane modification of CNTs is as follows. O-CNTs are dispersed in a silane solution via ultrasonication for $30 \mathrm{~min}$, which is then added to a mixture of ethanol/ water $(95: 5 \mathrm{v} / \mathrm{v})$. The reaction is conducted with stirring at $65^{\circ} \mathrm{C}$ for $4 \mathrm{~h}$. The resulting silanized CNTs are separated by filtration, washed with distilled water and acetone, and dried in a vacuum at $80^{\circ} \mathrm{C}$ for $20 \mathrm{~h} \mathrm{[30].}$

Lee et al. [26] studied silane modification of O-CNTs using 3-aminopropyltriethoxysilane (APTES). The surface modification and subsequent interactions with epoxy resin were characterized by FT-IR spectroscopy and SEM, respectively. The SEM results showed that the dispersion and impregnation of silanized CNTs in the epoxy resin were improved compared to the OCNTs. 
Table 6. Element composition of MWCNTs by EDS analysis [30]

\begin{tabular}{ccccccc} 
& \multicolumn{6}{c}{ Element (atom \%) } \\
\cline { 2 - 7 } Sample & $\mathrm{C}$ & $\mathrm{O}$ & $\mathrm{Al}$ & $\mathrm{Fe}$ & $\mathrm{Si}$ & $\mathrm{Si} / \mathrm{C}$ \\
\hline $\begin{array}{c}\text { P-MW- } \\
\text { CNTs }\end{array}$ & 94.53 & 4.68 & 0.42 & 0.38 & - & - \\
$\begin{array}{c}\text { S1-MW- } \\
\text { CNTs }\end{array}$ & 92.85 & 6.44 & 0.21 & 0.15 & 0.35 & 0.0038 \\
$\begin{array}{c}\text { S2-MW- } \\
\text { CNTs }\end{array}$ & 95.0 & 4.06 & 0.23 & 0.20 & 0.51 & 0.0054 \\
$\begin{array}{c}\text { S3-MW- } \\
\text { CNTs }\end{array}$ & 87.31 & 9.62 & 0.20 & 0.15 & 2.71 & 0.0310 \\
$\begin{array}{c}\text { S4-MW- } \\
\text { CNTs }\end{array}$ & 82.76 & 14.23 & - & 0.20 & 2.81 & 0.0340 \\
\hline
\end{tabular}

P-MWCNTs: pristine multi-walled carbon nanotubes, EDS: energydispersive X-ray spectroscopy, S1-MWCNTs: silanized MWCNTs (oxidized with $5 \mathrm{M} \mathrm{HNO}_{3}$ ), S2-MWCNTs: silanized MWCNTs (oxidized with $16 \mathrm{M} \mathrm{HNO}_{3}$, S3-MWCNTs: silanized MWCNTs (oxidized with $3 \mathrm{M} \mathrm{HNO}_{3}$, S4-MWCNTs: silanized MWCNTs (oxidized with $\mathrm{H}_{2} \mathrm{SO}_{4} / \mathrm{HNO}_{3}$ (3:1 by volume) solution.

Kim et al. [30] showed the silanization of O-MWCNTs, again using APTES. The results of energy-dispersive X-ray spectroscopy (EDS) analysis confirmed the attachment of the silane molecules to the surface of the O-MWCNTs, as shown in Table 6.

Kuan et al. [35] used a free radical reaction to silane-functionalize CNTs. FT-IR was used to monitor the reaction between the coupling agent and the CNTs. Solid-state ${ }^{29} \mathrm{Si}$ NMR spectroscopy revealed that the reactant components underwent a sol-gel reaction to form covalent bonds between the organic and inorganic phases.

\subsubsection{Fluorination of CNTs}

A general procedure for fluorinating CNTs is as follows. OMWCNTs $(1 \mathrm{~g}), 15 \mathrm{~mL}$ of 2-methoxyethyl ether, and $3.1 \mathrm{~mL}$ of 4-fluoroaniline are added to a flame-dried three-necked roundbottomed flask fitted with a condenser. While maintaining a $\mathrm{N}_{2}$ atmosphere, $4 \mathrm{~mL}$ of amyl nitrate is added slowly. The mixture is stirred at room temperature for $1 \mathrm{~h}$ and then the temperature is raised to $70^{\circ} \mathrm{C}$, followed by mixing for $3 \mathrm{~h}$. The product is cooled, diluted with diethyl ether, filtered, and then washed with copious amounts of distilled water. The wet product is dried in a vacuum at $60^{\circ} \mathrm{C}$ for $24 \mathrm{~h}$ [36].

Abdalla et al. [36] studied the link between the nature of the CNT surface modification and the quality of dispersion in an epoxy resin. Acid-treated and fluorinated MWCNTs were characterized by FT-IR and Raman spectroscopy, and SEM. The SEM images showed very good dispersion of the fluorinated CNTs in the epoxy matrix.

\subsubsection{Epoxy functionalization of CNTs}

A general procedure for epoxy functionalization of CNTs is as follows. O-CNTs $(2.00 \mathrm{~g})$ and $3.00 \mathrm{~g}$ of 4,4'-bis(2,3-epoxypropoxy)biphenyl (BP) epoxy resin are dispersed in $200 \mathrm{~mL}$ of tetrahydrofuran (THF) and then ultrasonicated in a $100 \mathrm{~W}$ bath sonicator at room temperature for $1 \mathrm{~h} . \mathrm{KOH}(8.96 \mathrm{~g})$ is added to the solution as a catalyst and the solution is refluxed at $70^{\circ} \mathrm{C}$ for $6 \mathrm{~h}$. The epoxy-functionalized CNTs are collected by filtration and then dried, resulting in a black powder [16].
Hsu et al. [16] functionalized CNTs using a liquid crystalline (LC) BP epoxy resin. The FT-IR spectra contained an epoxide ring peak, implying that not all of the rings opened and reacted during the functionalization process. TEM images of O-CNTs showed a rough and damaged surface, whereas those of epoxy functionalized CNTs showed a smoother surface.

2.2.5. Poly(glycidyl methacrylate) (PGMA)-grafted CNTs

A general procedure for the production of PGMA-grafted CNTs is as follows. CNTs, glycidyl methacrylate (GMA), and 2,2'-azobis-isobutyronitrile (AIBN) are mixed in a 6.2:1:1 molar ratio. The mixture is dispersed in $\mathrm{N}$-methylpyrrolidone and sonicated at $65^{\circ} \mathrm{C}$ in a $\mathrm{N}_{2}$ atmosphere for $2 \mathrm{~h}$, and then stirred for 24 h. After the reaction, the PGMA-grafted CNT slurry is washed several times with acetone to remove all non-grafted GMA, filtered, and then dried in a vacuum for $24 \mathrm{~h} \mathrm{[37].}$

Teng et al. [37] studied the thermal conductivity of epoxy composites containing both functionalized CNTs and aluminum nitride. XPS and SEM were used to investigate P-MWCNTs and GMA-grafted MWCNTs. SEM images indicated that an interconnected macro-nano binary network structure was constructed between the aluminum nitride and MWCNT fillers.

\subsubsection{Esterification of CNTs}

A general procedure for the esterification of CNTs is as follows. O-CNTs $(1 \mathrm{~g})$, phenyl glycidyl ether (PGE) (molar ratio $\mathrm{PGE} / \mathrm{COOH}=3$ ), and triphenyl phosphine (TPP) (molar ratio TPP/PGE $=0.2$ ) are dispersed in $200 \mathrm{ml}$ of THF. The esterification reaction is conducted with a refluxing solvent for $96 \mathrm{~h}$. After centrifugation and extensive washing with THF to remove unreacted PGE and TPP, the esterified nanotubes are dried in a vacuum at $90^{\circ} \mathrm{C}$ for $24 \mathrm{~h} \mathrm{[38].}$

Auad et al. [38] studied the esterification of both singlewalled CNTs (SWCNTs) and MWCNTs. TGA thermograms indicated that the organic mass attached to the carbon surface increased after the oxidation process because of the generation of carboxyl groups and increased further after esterification with PGE. Raman spectra demonstrated that the quality of the dispersion decreased in the following order: O-SWCNTs $>$ P-SWCNTs $>$ PGE-functionalized SWCNTs.

\section{Preparation Methods for Epoxy/CNT Com- posites}

The surface area of a CNT is several times greater than that of conventional fillers used in epoxy composites. This makes it difficult to homogenously disperse CNTs within the epoxy matrix and improve the interfacial bonding between the two components. Therefore, a key requirement for improved processing techniques for epoxy/CNT composites is the prevention of nanotube aggregation. Various investigations focusing on methods of mixing CNTs into the polymer matrix have been reported in the literature [39-48].

As previously mentioned, the principal methods for achieving dispersion of CNTs can be categorized as mechanical, physical, and chemical. Section 2 of this article dealt with chemical approaches to improving CNT dispersion. This section will focus on the mechanical methods currently under investigation, in- 
cluding ultrasonication and high-shear and high-impact mixing. It should be noted that mechanical methods do not permanently stabilize the dispersion [40].

Sonication is a commonly used technique for distributing CNTs in an epoxy matrix and involves the application of ultrasound energy to agitate particles in a solution. In the laboratory, it is usually achieved using an ultrasonic bath or an ultrasonic probe/horn. However, this technique is not easily scalable to industrial-level production, where other technologies, such as three-roll or ball mills, can assure a comparable high quality of mixing, together with the possibility of treating a large amount of material [39,41].

Recently, several methods have been developed for preparing epoxy/CNT composites with a high nanotube content, including the hot-press molding process, the mechanical densification method, and the layer-by-layer (LBL) method. In hot-press molding, a filtration system was employed to impregnate the epoxy resin into CNT buckypaper. In mechanical densification, vertically aligned CNT forests were densified followed by capillarity-induced wetting with epoxy resin. In the LBL method, the composites were formed on solid substrates by the sequential deposition of layers of oppositely charged polymers and CNTs [42].

The preparation methods for epoxy/CNT composites are discussed with respect to direct mixing processing and solution processing in the following sections.

\subsection{Direct mixing processing}

A general procedure for the direct mixing process is as follows. CNTs are added to epoxy resin and dispersed at an elevated temperature by application of intense shear forces (such as sonication or magnetic stirring). A curing agent is added to the epoxy/CNT mixture and agitated using magnetic stirring. To remove entrapped air and voids, the mixture is degassed in a vacuum. Finally, the mixture is transferred to silicone rubber molds and cured using the usual temperature profile.

Rahatekar et al. [43] studied the dispersion of CNTs in bisphenol A epoxy resin using high-shear mixing at $200 \mathrm{rpm}$ for $2 \mathrm{~h}$. Samples were cured at $60^{\circ} \mathrm{C}$ for $2 \mathrm{~h}$ and post-cured at $90^{\circ} \mathrm{C}$ for 15 $\mathrm{h}$. The optical microstructure showed a weak aggregation of CNTs as a result of unfavorable interactions with the epoxy matrix.

Gkikas et al. [40] used an ultrasonic mixer to disperse CNTs in epoxy resin. In order to avoid overheating and induction of defects on the CNT surfaces, the temperature of the mixture was kept low by submerging the container in an ice bath. Initial experiments were carried out for four different sonication time periods to thoroughly investigate the effect of the sonication conditions. The results showed that the duration and amplitude of the sonication process was of key importance for the dispersion of the CNTs in the epoxy resin.

Loos et al. [44] prepared suspensions of CNTs in epoxy resin with different amounts of block copolymers using a tip sonicator. SEM images showed that the dispersion of CNTs treated by block copolymers in the composites was enhanced.

Saw et al. [45] made transparent, electrically conductive, and flexible films by adding CNTs to the epoxy resin followed by sonication using a probe sonicator at room temperature. Optical micrographs showed that the short CNTs were well dispersed within the epoxy resin.

Gojny et al. [46] used a mini-calender and high-shear mix-

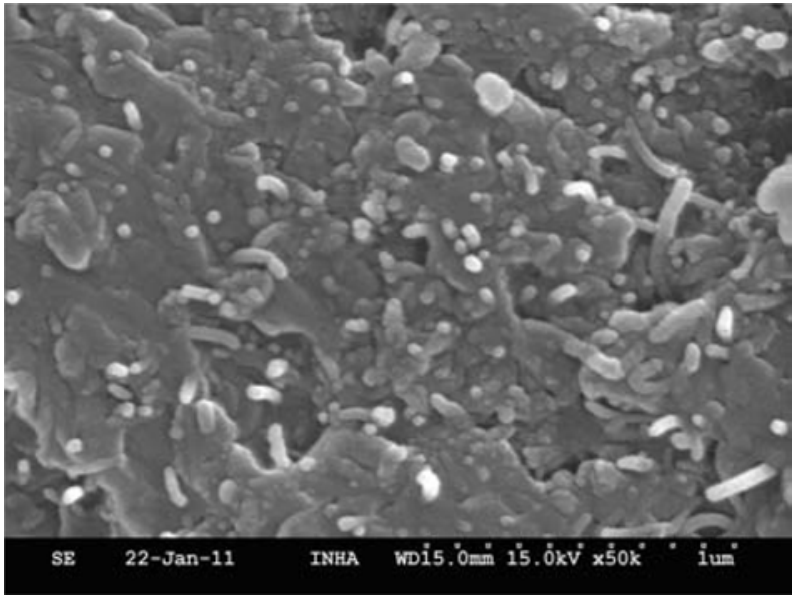

Fig. 4. Scanning electron microscope spectroscopy images of the frac ture surface in DGEBA/amino-CNT/DDM composites [17]. amino-CNTs: dodecyl amine functionalized carbon nanotubes.

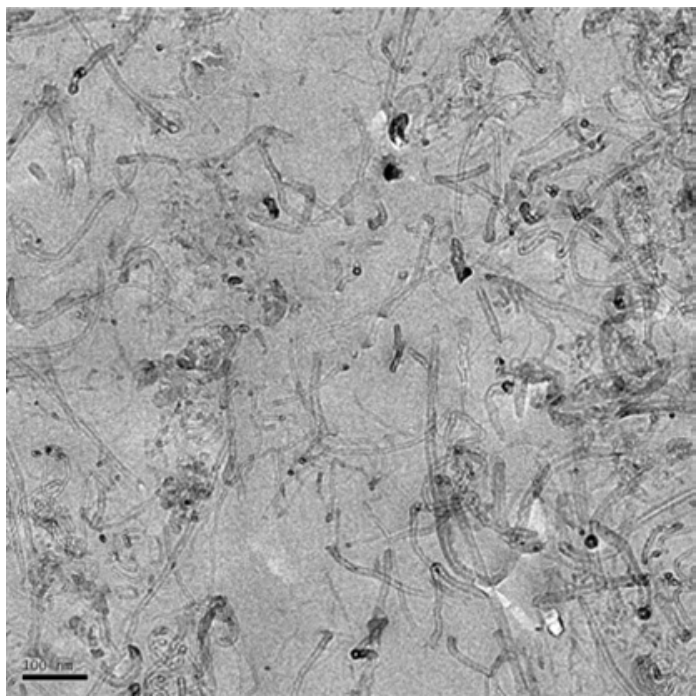

Fig. 5. Transmission electron microscopy photographs of DGEBA/amino-CNT/DDM composites [17]. amino-CNTs: dodecylamine functionalized carbon nanotubes.

ing to enhance the dispersibility of CNTs in epoxy resin. TEM images suggested that the amino groups stabilized the CNT dispersion by forming stronger interactions with the epoxy matrix.

Schulz et al. [39] produced CNT suspensions using two common dispersion methods, sonication using a horn ultrasonicator and milling by means of a 3-roll mill. Sonication is often used to produce small batches, whereas milling is more favorable for achieving good dispersion for larger amounts of material. Light microscopy images showed that milling was able to produce a fine and uniform dispersion of CNTs, but short sonication times were not able to break up the initial nanotube agglomerates.

Jin et al. [17] prepared epoxy/amino-CNT composites using a sonicator. As shown in Fig. 4, SEM images demonstrated that the amino-CNTs were well dispersed in the epoxy matrix. TEM micrographs also showed that the functionalized CNTs were separated and dispersed uniformly in the epoxy matrix, as shown in Fig. 5. 


\subsection{Solution processing}

A general procedure for solution processing of CNTs is as follows. CNTs are dispersed in a solvent using sonication and the resulting solution is added to epoxy resin and dispersed by the application of intense shear forces. The curing agent is then added to the epoxy/CNT mixture and magnetic stirring is used for further agitation. The resulting mixture is degassed at elevated temperature to eliminate the remaining solvent and trapped air. The composite resin is then molded in a steel mold and cured using the tracditional temperature profile.

Feng et al. [42] dispersed CNTs in $N, N$-dimethylformamide (DMF) using sonication. Epoxy composite films, 80-110 $\mu \mathrm{m}$ thick, with different CNT loadings were obtained using the mixed-curing-agent-assisted LBL method. SEM images showed that the high-loading CNTs were uniformly dispersed in the epoxy matrix.

Prolongo et al. [47] reported dispersion of CNTs in chloroform using magnetic stirring at $45^{\circ} \mathrm{C}$. Composites with different amino-CNTs contents were prepared with and without the pre-curing treatment. Field emission gun SEM (FEG-SEM) micrographs showed that the degree of dispersion achieved for the pre-cured samples was better than that for the non-treated samples.

Cividanes et al. [48] studied the dispersion of CNTs in acetone using an ultrasonicator bath and then mixing with epoxy resin. SEM micrographs showed that amine-functionalized CNTs had more disorganized microstructures, which led to greater dispersion of CNTs.

\section{Mechanical and Electrical Properties}

\subsection{Mechanical properties}

It is known that the mechanical performance of epoxy/CNT composites strongly depends on the uniformily of nanotube dispersion within the polymer matrix and the strong interfacial interactions between the two components $[22,23,47]$. It has been shown that functionalized CNTs are more readily dispersed in an epoxy matrix and have better interfacial interactions, which is beneficial for improving the properties of the composites [32].

Many researchers have reported that the formation of covalent bonding between functionalized CNTs and an epoxy matrix leads to more effective stress transfer and a denser crosslinked structure. This could limit the mobility of the matrix backbone and therefore improve the mechanical properties of epoxy composites [17]

Fracture toughness has been demonstrated to be improved by surface functionalization of CNTs, which was attributed to the improved interfacial bonding strength between the nanotubes and the epoxy matrix. This would lead to a suppression of debonding at the interface and crack propagation [49].

Many studies have shown that CNTs are able to elastically deform under relatively large stresses, both in tension and compression, leading to highly energy-absorbing processes. It has also been shown that the unique flexibility and geometric features of the CNTs contribute to continuous absorption of energy, resulting in increased elongation in the epoxy component $[18,50]$.

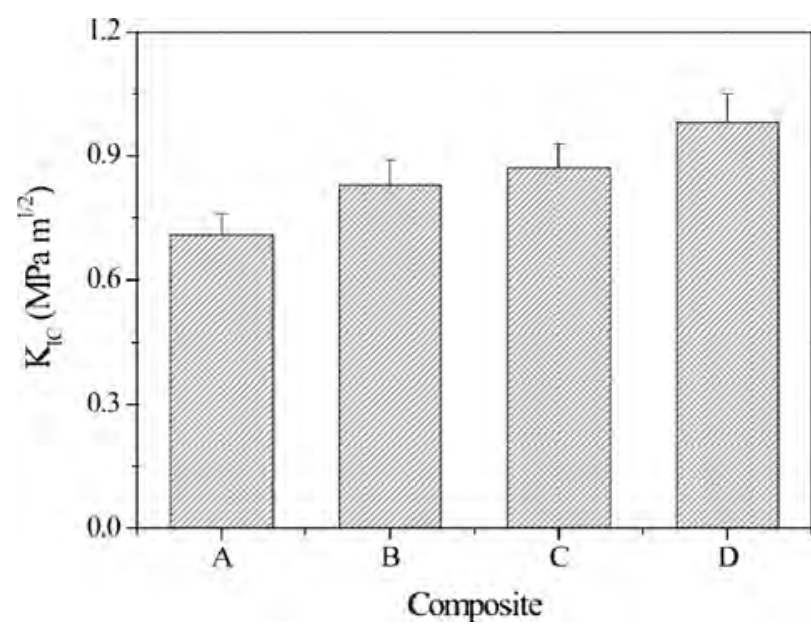

Fig. 6. $K_{1}$ values of DGEBA/CNT composites; (a) DGEBA/DDM, (b) DGEBA/P-CNT/DDM, (c) DGEBA/O-CNT/DDM, (d) DGEBA/amino-CNT/ DDM [17]. P-CNTs: pristine carbon nanotubes, O-CNTs: acid treated CNTs, amino-CNT: dodecylamine functionalized CNTs.

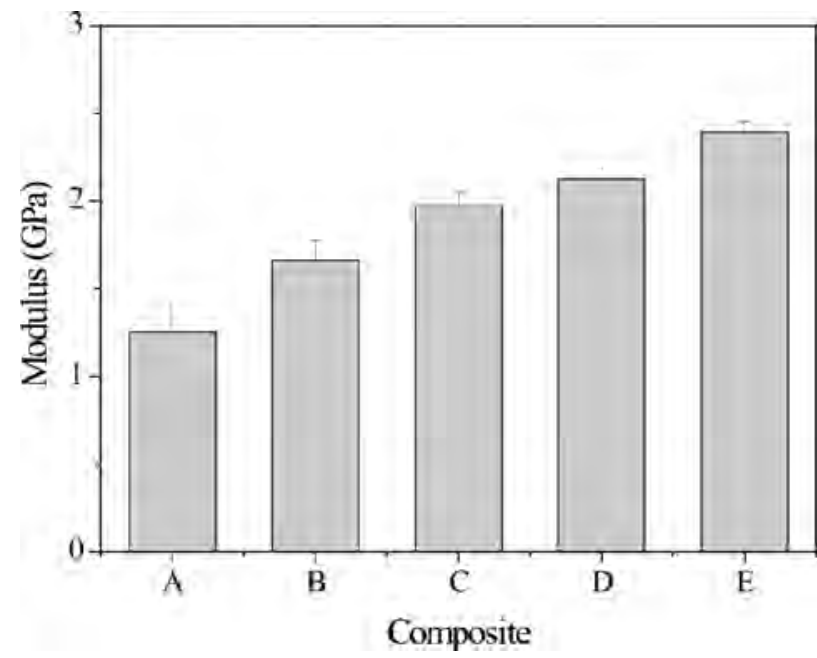

Fig. 7. Modulus of epoxy/CNT nanocomposites [51]. (a) Neat epoxy, (b) 0.5 wt\%-purified SWCNTs/epoxy, (c) $0.5 \mathrm{wt} \%$-biofunctionalized SWCNTs/ epoxy, (d) 1 wt\%-purified SWCNTs/epoxy, (e) 1 wt\%-biofunctionalized SWCNTs/epoxy. SWCNT: single-walled carbon nanotube.

Jin et al. [17] studied the mechanical interfacial properties of diglycidyl ether of bisphenol A (DGEBA) epoxy resin reinforced with amino-CNTs using critical stress intensity factor $\left(K_{\mathrm{IC}}\right)$ measurements. As shown in Fig. 6, the $K_{\mathrm{IC}}$ value of neat DGEBA was $0.71 \mathrm{MPa} \mathrm{m}{ }^{1 / 2}$. In contrast, the attained $K_{\mathrm{IC}}$ values of DGEBA/OCNT and DGEBA/amino-CNT composites were $22 \%$ higher, at $0.87 \mathrm{MPa} \mathrm{m}^{1 / 2}$, and $38 \%$ higher, at $0.98 \mathrm{MPa} \mathrm{m}^{1 / 2}$, respectively. These results were attributed to the improved dispersion of CNTs in the epoxy matrix and better interfacial interactions between the functional groups on the CNT surfaces and the polymer matrix.

Farahani et al. [51] investigated the use of biotin-streptavidin interactions to reinforce epoxy nanocomposites containing functionalized CNTs. The improvement of the tensile modulus for epoxy/CNT composites with $1 \mathrm{wt} \%$ biofunctionalized CNT loading was $93 \%$ in a comparison to that of the neat epoxy resin, as shown in Fig. 7. The increased stiffness could be attributed 
Table 7. Hardness of ef-CNT/epoxy/DDS composites [16]

\begin{tabular}{ccccccc} 
ef-CNT content $(\mathrm{wt} \%)$ & 0.0 & 0.5 & 1.0 & 2.0 & 4.0 & 10.0 \\
\hline Hardness & $16.62 \pm 0.48$ & $20.99 \pm 0.5$ & $24.52 \pm 0.8$ & $27.14 \pm 1.22$ & $27.86 \pm 2.2$ & $28.02 \pm 1.8$ \\
\hline
\end{tabular}

ef-CNT: epoxy functionalized carbon nanotube, DDS: diaminodiphenylsulfone.

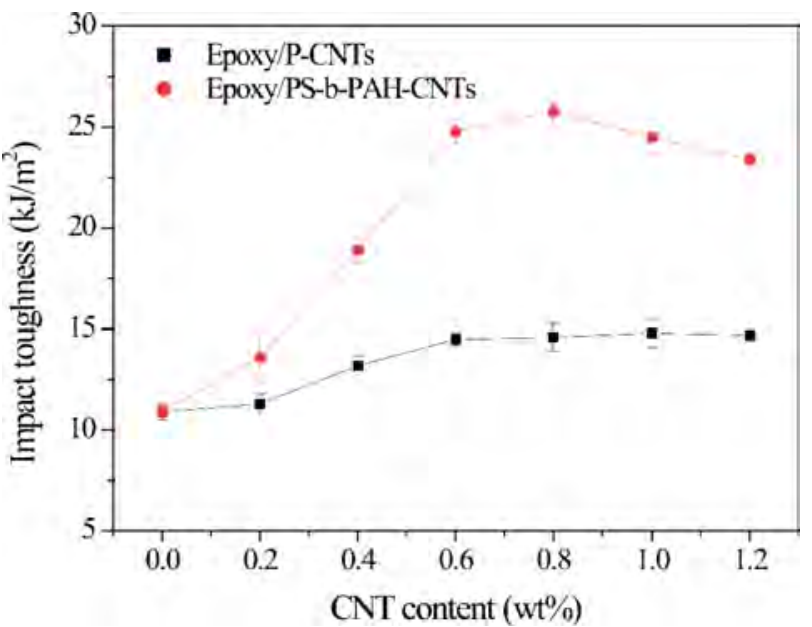

Fig. 8. Effect of CNT content on impact toughness of epoxy/CNT composites [19]. PS-b-PAH-CNTs: poly(styrene-b-pyrene) (PS-b-PAH) modified carbon nanotubes.

to the proper dispersion, as well as beneficial orientation, of the nanotubes that may occur during the extrusion of the composite through the micronozzle.

Hsu et al. [16] assessed the mechanical properties of biphenyl liquid crystalline epoxy/CNTs composites. As shown in Table 7, the Vickers hardness of the neat epoxy resin was only $16.62 \mathrm{Hv}$, whereas that of the composite with $2.00 \mathrm{wt} \%$ epoxy-functionalized CNTs (ef-CNTs) was $63 \%$ higher, at $27.14 \mathrm{Hv}$. This was the result of homogeneous dispersion of the CNTs and improved rigidity and hardness via improved interfacial interaction with the epoxy matrix.

Luan et al. [19] studied the effect of pyrene-modified MWCNTs on the properties of epoxy composites. Fig. 8 shows the effect of MWCNT content on the impact toughness of the composites. Compared with the neat resin, the impact toughness values of P-CNT composite and poly(styrene-b-pyrene) (PS-bPAH) modified CNT composite were improved by $33.09 \%$ and $127.94 \%$, respectively, when the CNT content was increased to $0.6 \mathrm{wt} \%$. SEM images of the epoxy/PS-b-PAH modified CNT composite indicated that the block copolymer modifier acted as a dispersant of the MWCNTs within the matrix.

Kwon et al. [52] studied the dispersion, hybrid interconnection, and heat dissipation properties of functionalized CNTs in epoxy composites. The mechanical characteristics of the composites were confirmed by measuring the mechanical strengths of completely interconnected quad flat packages (QFPs). Fig. 9 shows the pull strength data for the QFP solder joints for all epoxy/CNT composites. In the case of DGEBA, the pull strengths of P-CNT, O-CNT, and amino-CNT composites were 6.6, 11.2, and $12.6 \mathrm{~N}$, respectively. The pull strength of the DGEBA/amino-CNT composite was twice as high as that of the composite containing P-CNTs. This can be attributed to the strong covalent

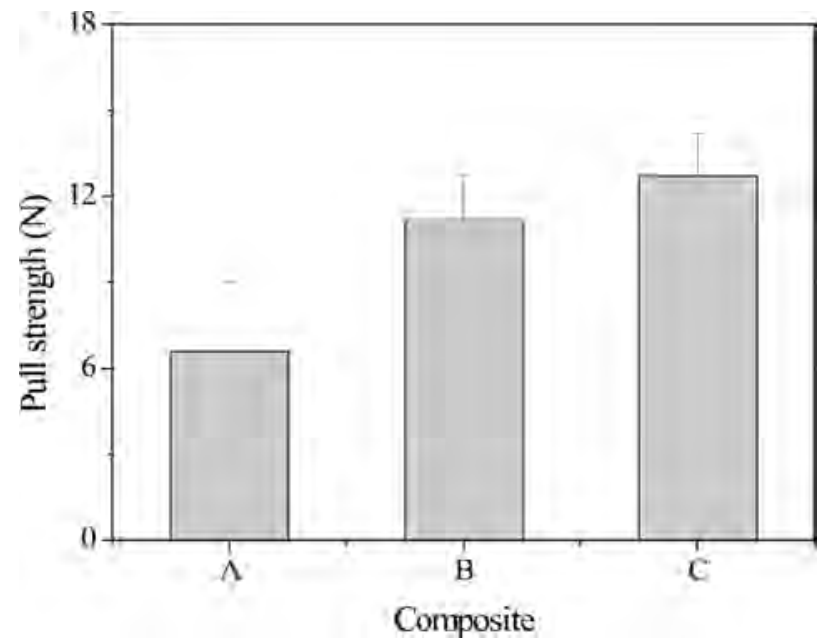

Fig. 9. Pull strengths of the quad flat package leads [52]. (a) Epoxy/PCNTs, (b) epoxy/A-CNTs, (c) epoxy/Amine-CNTs. P-CNTs: pristine carbon nanotubes, A-CNTs: acid treated CNTs, D-CNTs: amine functionalized CNTs.

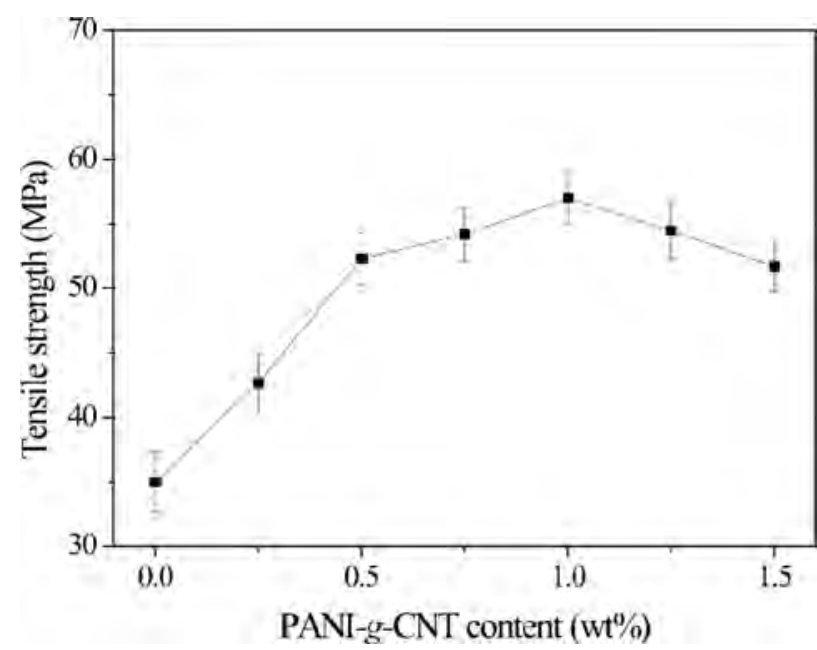

Fig. 10. Tensile strength of epoxy composites as a function of PANI-gMWCNT content [53]. PANI-g-MWCNTs: polyaniline-grafted multiwalled carbon nanotubes.

bonds formed between the amino groups on the CNT surfaces and the epoxy matrix, which resulted in improved mechanical properties.

$\mathrm{Xu}$ et al. [53] studied the tensile strength of conducting epoxy/polyaniline-grafted CNT (PANI-g-CNT) composites. As shown in Fig. 10, the tensile strength increased by $61 \%$ from 35.26 (neat epoxy) to $56.93 \mathrm{MPa}$, when the PANI-g-CNT content was raised from 0 to $1 \mathrm{wt} \%$. This was attributed to the reaction of amino groups on the CNT surfaces with the epoxy matrix 


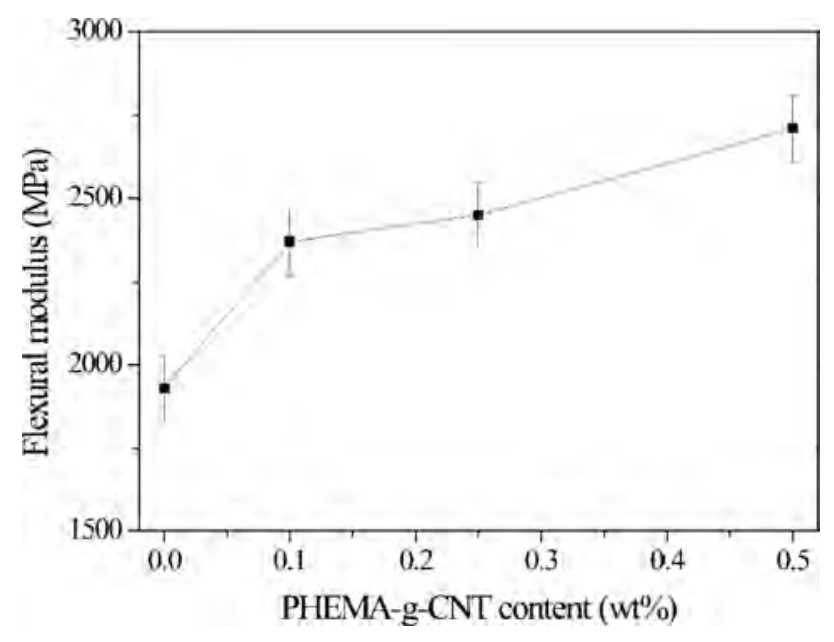

Fig. 11. Flexural modulus of epoxy/CNT nanocomposites [23]. PHEMAg-CNTs: poly(2-hydroxyethyl methacrylate) grafted multi-walled carbon nanotubes.

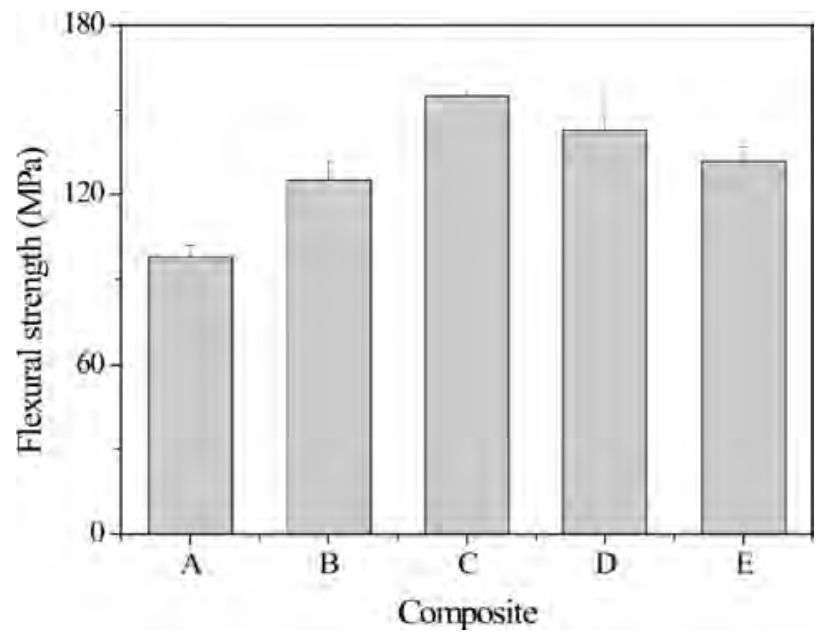

Fig. 12. Ultimate flexural strength neat epoxy resin, non-treated and thermal pre-cured carbon nanotube (CNT)/epoxy composites [47]. (a) DGEBA/DDS, (b) DGEBA/CNT/DDS (0.25 wt\% CNTs), (c) DGEBA/CNT/ DDS (0.25 wt \% CNTs, pre-cured), (d) DGEBA/CNT/DDS (0.4 wt\% CNTs), (e) DGEBA/CNT/DDS (0.4 wt\% CNTs, pre-cured).

during curing, providing interfacial adhesion for load transfer between the polymer and the nanotubes.

$\mathrm{Xu}$ et al. [23] reported the reinforcement of epoxy nanocomposites with poly-(2-hydroxyethyl methacrylate) (PHEMA)grafted CNTs (PHEMA-g-CNTs). Fig. 11 shows the flexural moduli of the epoxy/PHEMA-g-CNT nanocomposites as a function of CNT content. The results revealed that the flexural modulus increased steadily with the amount of CNTs incorpareted, as a result of stronger interfacial interactions between the PHEMA-g-MWCNTs and the epoxy matrix, which enabled a more effective transfer of stress from the polymer to the CNTs.

Prolongo et al. [47] studied the flexural properties of epoxy/ amino-CNT composites prepared using a pre-curing treatment. As shown in Fig. 12, the epoxy resin reinforced with $0.40 \%$ CNTs exhibited an increase of $45 \%$ in flexural strength. However, at lower CNT contents, the composite with $0.25 \%$ CNTs, which was subjected to pre-curing thermal treatment, showed

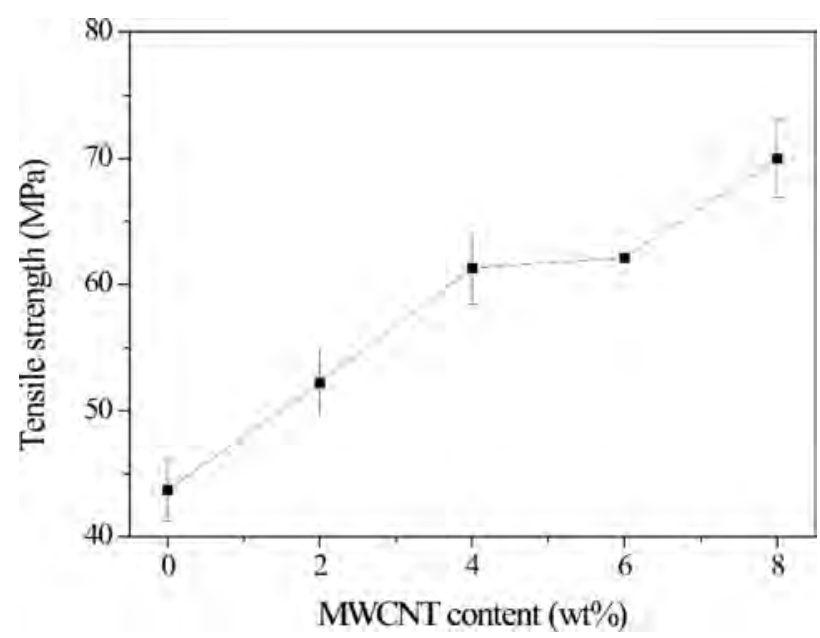

Fig. 13. Effects of MWCNT content on tensile strength of epoxy/MWCNT composites [54]. MWCNTs: multi-walled carbon nanotubes.

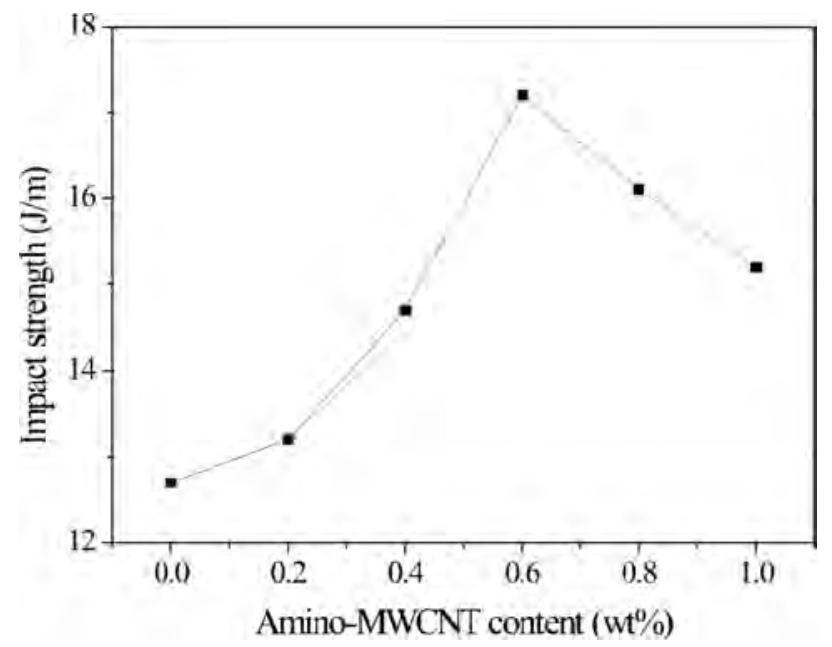

Fig. 14. Impact strength of epoxy/MWCNT nanocomposites with different amino-MWCNT content [55]. amino-MWCNTs: amine functionalized multi-walled carbon nanotubes.

improved mechanical properties, with a $58 \%$ increase in strength over the pristine epoxy resin. This indicated that the pre-curing treatment induced interfacial bonding, enabling effective stress transfer between the epoxy matrix and the amino-functionalized CNTs.

Guo et al. [54] investigated the effects of MWCNT addition and surface modification on the mechanical performance of epoxy/MWCNT composites. As shown in Fig. 13, the tensile strength of the composites improved with an increasing MWCNT addition. In addition, the fracture strain was also distinctly enhanced, implying that MWCNT loading not only elevated the tensile strength of the epoxy matrix but also increased the fracture toughness.

Kim and Park [55] studied the effect of amino-MWCNTs on the mechanical interfacial properties of epoxy nanocomposites. The impact strengths of epoxy/amino-MWCNT composites with different nanotube content are shown in Fig. 14. The impact strengths of the nanocomposites were remarkably improved with increasing the amino-MWCNT content up to $0.6 \mathrm{wt} \%$. 


\begin{tabular}{|c|c|c|}
\hline Type of composites & PAni content (wt $\%$ ) & $\begin{array}{c}\text { Electrical } \\
\text { conductivity }(\mathrm{s} / \mathrm{cm})\end{array}$ \\
\hline $\mathrm{P}-\mathrm{CNTs} / \mathrm{EP}$ & 0 & 0.39 \\
\hline PAni/EP & 100 & 0 \\
\hline PAni-O-CNTs/EP & 6.1 & 0.08 \\
\hline PAni-K-CNTs/EP & 1.2 & 0.34 \\
\hline PAni-K-O-CNTs/EP & 8.9 & 0.06 \\
\hline PAni-S-CNTs/EP & 0.6 & 0.39 \\
\hline PAni-S-O-CNTs/EP & 5.6 & 0.07 \\
\hline
\end{tabular}

P-CNTs: pristine carbon nanotubes, EP: epoxy, PAni: polyaniline, PAniO-CNTs: PAni coated oxidized CNTs, PAni-K-CNTs: PAni coated KPS treated CNTs, PAni-K-O-CNTs: PAni coated KPS treated oxidized CNTs, PAni-S-CNTs: PAni coated SDS treated CNTs, PAni-S-O-CNTs: PAni coated SDS treated oxidized CNTs.

\subsection{Electrical properties}

CNTs exhibit excellent electrical properties (of the order of $10^{3}-10^{4} \mathrm{~S} / \mathrm{cm}$ ). Their high conductivity makes them excellent candidates for producing conductive polymer composites. The formation of an electrically conductive nanotube pathway in a polymer composite is characterized by the percolation threshold, which is the minimum concentration of conductive filler required to form a three-dimensional network $[52,56]$. It is well known that the percolation thresholds of polymer/CNT composites in general depend on the aspect ratio of the conducting fillers and degree of dispersion of CNTs. The higher the aspect ratio is, the lower the percolation threshold. Experimental results have shown that homogenous dispersion and alignment of CNTs in the matrix increases the electrical conductivity of CNT-filled composites. Moreover, the conductivity continues to increase with an increasing CNT content, even after the percolation threshold has been reached $[42,45]$.

Park et al. [20] studied the effects on the electrical properties of epoxy/CNT composites of coating the CNTs with polyaniline (PAni-CNTs). As shown in Table 8, the epoxy/P-CNT composite exhibited the highest conductivity among those tested, with the conductivity decreasing with an increasing PAni coating thickness. The epoxy/PAni-coated, potassium persulfate treated O-CNTs (PAni-K-O-CNTs) composite showed the lowest electrical conductivity among the composites as a result of the presence of a thicker electrically insulating layer.

Liu et al. [57] reported MWCNT-reinforced epoxy composites with polyethylenimine as a dispersant. Fig. 15 shows the electrical conductivities of the epoxy/MWCNT-polyethylenimine composites. The covalently modified composites were 10000 times more resistive than their non-covalent counterparts. The storage moduli of the composites containing covalently functionalized nanotubes increased relative to the non-covalent composites, as a result of the stronger polymer-nanotube interactions.

Bai and Allaoui [58] studied the effect of CNT length and aggregate size on the electrical properties of epoxy/CNT compos-

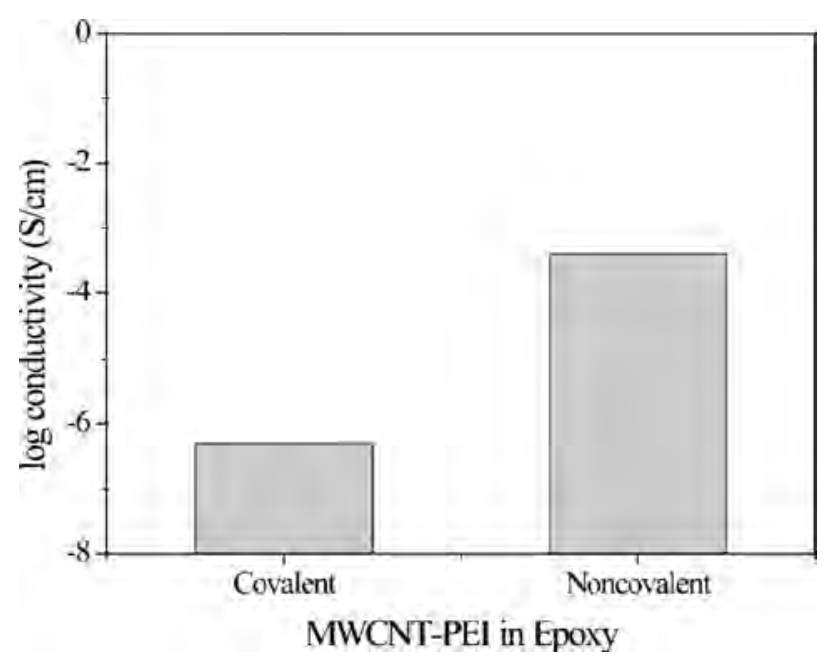

Fig. 15. Electrical conductivity and modulus of epoxy/CNT-PEI composites [57]. CNT-PEls: polyethylenimine grafted multi-walled carbon nanotubes.

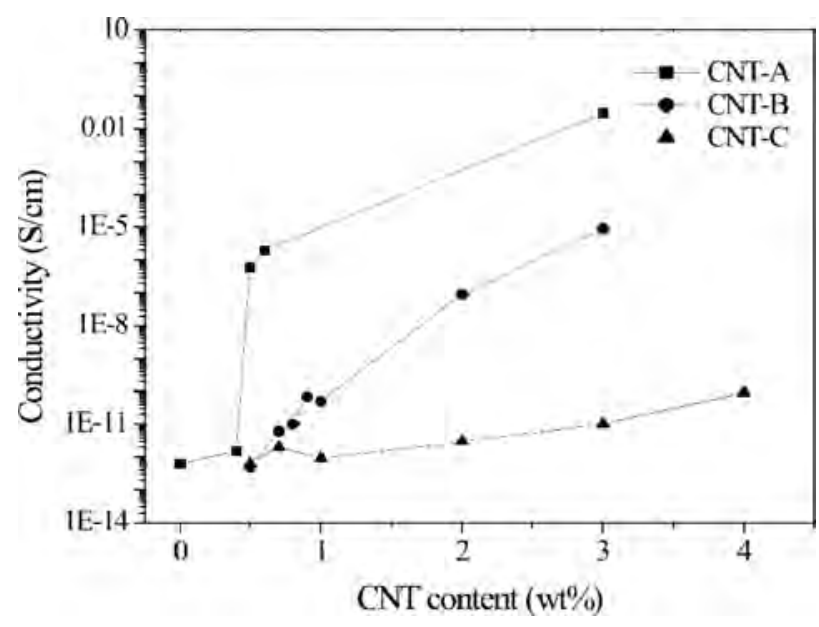

Fig. 16. Evolution of conductivity of epoxy/carbon nanotube (CNT) composites as a function of CNT content for three treatments [58].

ites. The insulator-to-conductor transition occurred at $0.5 \mathrm{wt} \%$ P-MWCNTs, as shown in Fig. 16.

Lee et al. [26] studied the effects of silane modification of CNTs on the electrical properties of epoxy/carbon/CNT threephase composites. Fig. 17 shows the volume resistivities of the epoxy/carbon/unmodified, oxidized, and silanized CNT composites, which were $2.8,1.5$, and $0.6 \Omega \cdot \mathrm{cm}$, respectively. The lower volume resistivity of the silanized composites may be a result of the formation of a continuous network structure caused by homogeneous dispersibility of CNTs between the carbon fibers.

$\mathrm{Xu}$ et al. [53] studied the electrical properties of conducting epoxy/PANI-g-MWCNT composites. The electrical conductivity for neat epoxy is $2.848 \times 10^{-13} \mathrm{~S} / \mathrm{cm}$. Incorporation of 1.0 $\mathrm{wt} \%$ PANI-g-MWCNTs increased this by seven orders of magnitude to $1.975 \times 10^{-6} \mathrm{~S} / \mathrm{cm}$. This increase in electrical conductivity implies that the percolation threshold for the composites was between 0.25 and $1.0 \mathrm{wt} \%$ of PANI-g-MWCNT content. Because of the encapsulation by the swelling PANI coatings, 


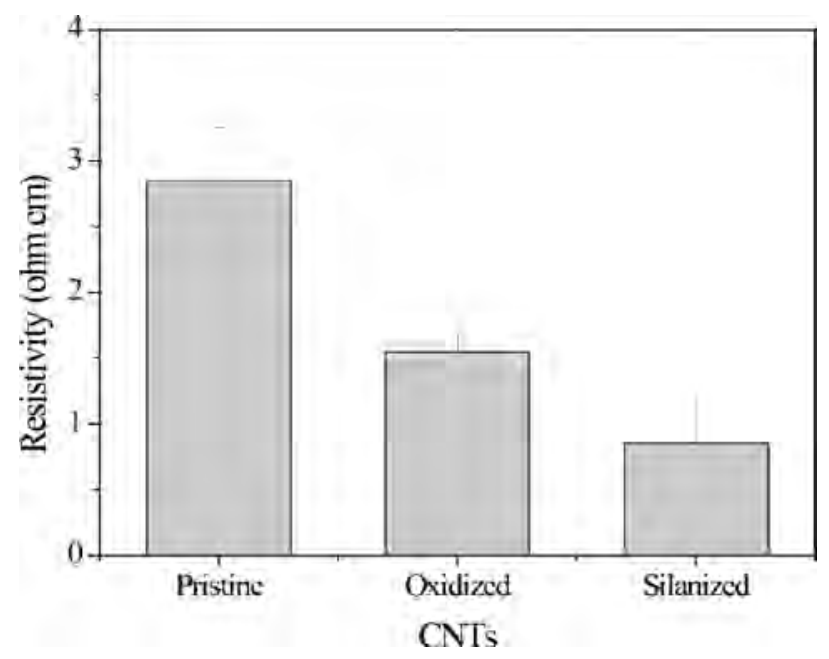

Fig. 17. Volume resistivities of epoxy/carbon/unmodified, oxidized, and silanized carbon nanotube (CNT) composites [26].

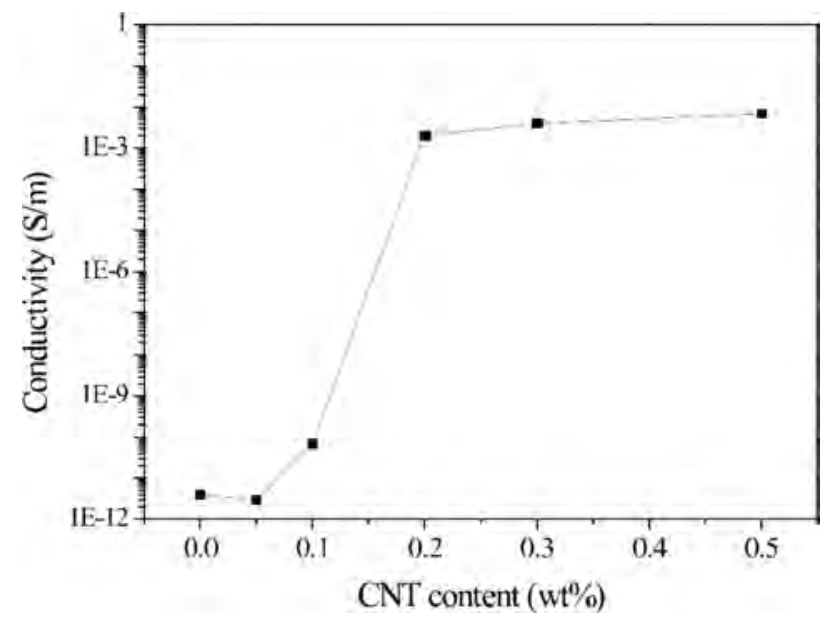

Fig. 18. Conductivity of carbon nanotube (CNT)/epoxy composites prepared by sonication aided dispersion at $120^{\circ} \mathrm{C}$ vs. CNT content [41].

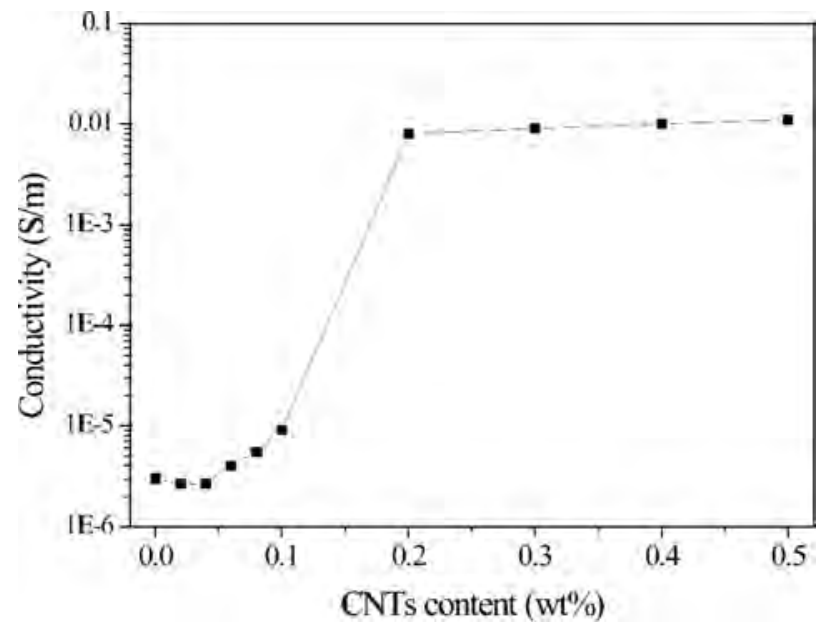

Fig. 19. Electrical conductivity of epoxy/multi-walled carbon nanotubes (MWCNT) composites as a function of MWCNT content [45].
PANI-g-MWCNTs could not aggregate and were homogenously dispersed in the epoxy resin, resulting in formation of electrical networks.

Martone et al. [41] studied the electrical conductivity of epoxy/MWCNT nanocomposites. Fig. 18 shows the electrical conductivities of the nanocomposites as a function of MWCNT content. A percolative transition between the insulating and conducting behaviour occurred above $0.1 \mathrm{wt} \%$ MWCNTs.

Saw et al. [45] prepared transparent, electrically conductive, and flexible films from epoxy/MWCNT composites. Fig. 19 shows the electrical conductivities of the composite films plotted as a function of CNT content for two different types of CNT. The conductivity increased with increasing CNT content and there was a jump in conductivity by almost four orders of magnitude when the CNT content reached $1 \mathrm{wt} \%$. After the percolation threshold was reached, the electrical conductivity showed a further gradual increase.

\section{Conclusions}

In this paper, we have reviewed the surface modification of CNTs, processing methods, and mechanical and electrical properties of epoxy/CNT composites. The surfaces of CNTs were treated using oxidation and chemical treatment methods to improve the dispersion stability of CNTs and interactions between them and epoxy resins. The electrical and mechanical properties of the composites were significantly improved by the addition of CNTs. CNT-based epoxy composites are of great interest as multifunctional high-performance materials for use in aircraft and electronic products.

\section{References}

[1] Bauer RS. Preface. In: Bauer RS, ed. Epoxy resin chemistry, ACS Symposium Series Vol. 114, American Chemical Society, Washington, DC, ix (1979). http://dx.doi.org/10.1021/bk-1979-0114. pr001.

[2] Serrano E, Tercjak A, Kortaberria G, Pomposo JA, Mecerreyes D, Zafeiropoulos NE, Stamm M, Mondragon I. Nanostructured thermosetting systems by modification with epoxidized styrene-butadiene star block copolymers. Effect of epoxidation degree. Macromolecules, 39, 2254 (2006). http://dx.doi.org/10.1021/ma0515477.

[3] Chen JL, Jin FL, Park SJ. Thermal stability and impact and flexural properties of epoxy resins/epoxidized castor oil/nano- $\mathrm{CaCO}_{3}$ ternary systems. Macromol Res, 18, 862 (2010). http://dx.doi. org/10.1007/s13233-010-0911-4

[4] Jin FL, Park SJ. Thermal stability of trifunctional epoxy resins modified with nanosized calcium carbanate. Bull Korean Chem Soc, 30, 334 (2009). http://dx.doi.org/10.5012/bkcs.2009.30.2.334.

[5] Iijima S. Helical microtubules of graphitic carbon. Nature, 354, 56 (1991). http://dx.doi.org/10.1038/354056a0.

[6] Ajayan PM, Stephan O, Colliex C, Trauth D. Aligned carbon nanotube arrays formed by cutting a polymer resin--nanotube composite. Science, 265, 1212 (1994). http://dx.doi.org/10.1126/ science.265.5176.1212.

[7] Zhang J, Zou H, Qing Q, Yang Y, Li Q, Liu Z, Guo X, Du Z. Effect of chemical oxidation on the structure of single-walled car- 
bon nanotubes. J Phys Chem B, 107, 3712 (2003). http://dx.doi. org/10.1021/jp027500u.

[8] Hong J, Park DW, Shim SE. A review on thermal conductivity of polymer composites using carbon-based fillers: carbon nanotubes and carbon fibers. Carbon Lett, 11, 347 (2010). http://dx.doi. org/10.5714/CL.2010.11.4.347.

[9] Jin FL, Park SJ. A review of the preparation and properties of carbon nanotubes-reinforced polymer compositess. Carbon Lett, 12, 57 (2011). http://dx.doi.org/10.5714/CL.2011.12.2.057.

[10] Zhang X, Zhang J, Wang R, Liu Z. Cationic surfactant directed polyaniline/CNT nanocables: synthesis, characterization, and enhanced electrical properties. Carbon, 42, 1455 (2004). http:// dx.doi.org/10.1016/j.carbon.2004.01.003.

[11] Spitalsky Z, Tasis D, Papagelis K, Galiotis C. Carbon nanotubepolymer composites: chemistry, processing, mechanical and electrical properties. Prog Polym Sci, 35, 357 (2010). http://dx.doi. org/10.1016/j.progpolymsci.2009.09.003.

[12] Kim KS, Park SJ. Influence of enhanced dispersity of chemically treated MWNTs on physical properties of MWNTs/PVDF films. Macromol Res, 18, 981 (2010).

[13] Lee YS, Im JS, Yun SM, Nho YC, Kang PH, Jin H. X-ray photoelectron spectroscopic analysis of modified MWCNT and dynamic mechanical properties of e-beam cured epoxy resins with the MWCNT. Carbon Lett, 10, 314 (2009). http://dx.doi.org/10.5714/ CL.2009.10.4.314

[14] Sahoo NG, Rana S, Cho JW, Li L, Chan SH. Polymer nanocomposites based on functionalized carbon nanotubes. Prog Polym Sci, 35, 837 (2010). http://dx.doi.org/10.1016/j.progpolymsci.2010.03. 002 .

[15] Jung HT, Cho Y, Kim T, Kim TA, Park M. Preparation of amineepoxy adducts(AEA)/thin multiwalled carbon nanotubes (MWCNTs) composite particles using dry processes. Carbon Lett, 11, 107 (2010). http://dx.doi.org/10.5714/CL.2010.11.2.107.

[16] Hsu SH, Wu MC, Chen S, Chuang CM, Lin SH, Su WF. Synthesis, morphology and physical properties of multi-walled carbon nanotube/biphenyl liquid crystalline epoxy composites. Carbon, 50, 896 (2012). http://dx.doi.org/10.1016/j.carbon.2011.09.051.

[17] Jin FL, Ma CJ, Park SJ. Thermal and mechanical interfacial properties of epoxy composites based on functionalized carbon nanotubes. Mater Sci Eng A, 528, 8517 (2011). http://dx.doi. org/10.1016/j.msea.2011.08.054.

[18] Liu L, Wagner HD. Rubbery and glassy epoxy resins reinforced with carbon nanotubes. Compos Sci Technol, 65, 1861 (2005). http://dx.doi.org/10.1016/j.compscitech.2005.04.002.

[19] Luan J, Zhang A, Zheng Y, Sun L. Effect of pyrene-modified multiwalled carbon nanotubes on the properties of epoxy composites. Composites A, 43, 1032 (2012). http://dx.doi.org/10.1016/j.compositesa.2012.02.005.

[20] Park OK, Kim NH, Yoo GH, Rhee KY, Lee JH. Effects of the surface treatment on the properties of polyaniline coated carbon nanotubes/epoxy composites. Composites B, 41, 2 (2010). http://dx.doi. org/10.1016/j.compositesb.2009.10.002.

[21] Barghamadi M, Behmadi H. Influence of the epoxy functionalization of multiwall carbon nanotubes on the nonisothermal cure kinetics and thermal properties of epoxy/multiwall carbon nanotube nanocomposites. Polym Compos, 33, 1085 (2012). http://dx.doi. org $/ 10.1002 / \mathrm{pc} .22232$

[22] Ma PC, Mo SY, Tang BZ, Kim JK. Dispersion, interfacial interaction and re-agglomeration of functionalized carbon nanotubes in epoxy composites. Carbon, 48, 1824 (2010). http://dx.doi. org/10.1016/j.carbon.2010.01.028.

[23] Xu L, Fang Z, Song Pa, Peng M. Functionalization of carbon nanotubes by corona-discharge induced graft polymerization for the reinforcement of epoxy nanocomposites. Plasma Processes Polym, 7, 785 (2010). http://dx.doi.org/10.1002/ppap.201000019.

[24] Yang SY, Ma CCM, Teng CC, Huang YW, Liao SH, Huang YL, Tien HW, Lee TM, Chiou KC. Effect of functionalized carbon nanotubes on the thermal conductivity of epoxy composites. Carbon, 48, 592 (2010). http://dx.doi.org/10.1016/j.carbon.2009.08.047.

[25] Wang J, Fang Z, Gu A, Xu L, Liu F. Effect of amino-functionalization of multi-walled carbon nanotubes on the dispersion with epoxy resin matrix. J Appl Polym Sci, 100, 97 (2006). http://dx.doi. org/10.1002/app.22647.

[26] Lee JH, Rhee KY, Park SJ. Silane modification of carbon nanotubes and its effects on the material properties of carbon/CNT/epoxy three-phase composites. Composites A, 42, 478 (2011). http:// dx.doi.org/10.1016/j.compositesa.2011.01.004.

[27] Spitalsky Z, Matejka L, Slouf M, Konyushenko EN, Kovarova J, Zemek J, Kotek J. Modification of carbon nanotubes and its effect on properties of carbon nanotube/epoxy nanocomposites. Polym Compos, 30, 1378 (2009). http://dx.doi.org/10.1002/pc.20701.

[28] Hadjiev VG, Warren GL, Sun L, Davis DC, Lagoudas DC, Sue HJ. Raman microscopy of residual strains in carbon nanotube/epoxy composites. Carbon, 48, 1750 (2010). http://dx.doi.org/10.1016/j. carbon.2010.01.018.

[29] Luo Y, Zhao Y, Cai J, Duan Y, Du S. Effect of amino-functionalization on the interfacial adhesion of multi-walled carbon nanotubes/epoxy nanocomposites. Mater Design, 33, 405 (2012). http:// dx.doi.org/10.1016/j.matdes.2011.04.033.

[30] Kim HC, Kim SK, Kim JT, Rhee KY, Kathi J. The effect of different treatment methods of multiwalled carbon nanotubes on thermal and flexural properties of their epoxy nanocomposites. J Polym Sci B, 48, 1175 (2010). http://dx.doi.org/10.1002/polb.22007.

[31] Peng K, Liu LQ, Li H, Meyer H, Zhang Z. Room temperature functionalization of carbon nanotubes using an ozone/water vapor mixture. Carbon, 49, 70 (2011). http://dx.doi.org/10.1016/j.carbon.2010.08.043.

[32] Yaping Z, Aibo Z, Qinghua C, Jiaoxia Z, Rongchang N. Functionalized effect on carbon nanotube/epoxy nano-composites. Mater Sci Eng A, 435-436, 145 (2006). http://dx.doi.org/10.1016/j. msea.2006.07.106

[33] Armstrong G, Ruether M, Blighe F, Blau W. Functionalised multi-walled carbon nanotubes for epoxy nanocomposites with improved performance. Polym Int, 58, 1002 (2009). http://dx.doi. org/10.1002/pi.2621.

[34] Yang K, Gu M. The effects of triethylenetetramine grafting of multi-walled carbon nanotubes on its dispersion, filler-matrix interfacial interaction and the thermal properties of epoxy nanocomposites. Polym Eng Sci, 49, 2158 (2009). http://dx.doi.org/10.1002/ pen.21461.

[35] Kuan CF, Chen WJ, Li YL, Chen CH, Kuan HC, Chiang CL. Flame retardance and thermal stability of carbon nanotube epoxy composite prepared from sol-gel method. J Phys Chem Solids, 71, 539 (2010). http://dx.doi.org/10.1016/j.jpcs.2009.12.031.

[36] Abdalla M, Dean D, Adibempe D, Nyairo E, Robinson P, Thompson G. The effect of interfacial chemistry on molecular mobility and morphology of multiwalled carbon nanotubes epoxy nanocomposite. Polymer, 48, 5662 (2007). http://dx.doi.org/10.1016/j. 
polymer.2007.06.073.

[37] Teng CC, Ma CCM, Chiou KC, Lee TM. Synergetic effect of thermal conductive properties of epoxy composites containing functionalized multi-walled carbon nanotubes and aluminum nitride. Composites B, 43, 265 (2012). http://dx.doi.org/10.1016/j.compositesb.2011.05.027.

[38] Auad ML, Mosiewicki MA, Uzunpinar C, Williams RJJ. Functionalization of carbon nanotubes and carbon nanofibers used in epoxy/amine matrices that avoid partitioning of the monomers at the fiber interface. Polym Eng Sci, 50, 183 (2010). http://dx.doi. org/10.1002/pen.21509.

[39] Schulz SC, Faiella G, Buschhorn ST, Prado LASA, Giordano M, Schulte K, Bauhofer W. Combined electrical and rheological properties of shear induced multiwall carbon nanotube agglomerates in epoxy suspensions. Eur Polym J, 47, 2069 (2011). http://dx.doi. org/10.1016/j.eurpolymj.2011.07.022.

[40] Gkikas G, Barkoula NM, Paipetis AS. Effect of dispersion conditions on the thermo-mechanical and toughness properties of multi walled carbon nanotubes-reinforced epoxy. Composites B, 43, 2697 (2012). http://dx.doi.org/10.1016/j.compositesb.2012.01.070.

[41] Martone A, Formicola C, Giordano M, Zarrelli M. Reinforcement efficiency of multi-walled carbon nanotube/epoxy nano composites. Compos Sci Technol, 70, 1154 (2010). http://dx.doi. org/10.1016/j.compscitech.2010.03.001.

[42] Feng QP, Yang JP, Fu SY, Mai YW. Synthesis of carbon nanotube/ epoxy composite films with a high nanotube loading by a mixedcuring-agent assisted layer-by-layer method and their electrical conductivity. Carbon, 48, 2057 (2010). http://dx.doi.org/10.1016/j. carbon.2010.02.016

[43] Rahatekar SS, Zammarano M, Matko S, Koziol KK, Windle AH, Nyden M, Kashiwagi T, Gilman JW. Effect of carbon nanotubes and montmorillonite on the flammability of epoxy nanocomposites. Polym Degrad Stab, 95, 870 (2010). http://dx.doi.org/10.1016/j. polymdegradstab.2010.01.003.

[44] Loos MR, Yang J, Feke DL, Manas-Zloczower I. Effect of blockcopolymer dispersants on properties of carbon nanotube/epoxy systems. Compos Sci Technol, 72, 482 (2012). http://dx.doi. org/10.1016/j.compscitech.2011.11.034.

[45] Saw LN, Mariatti M, Azura AR, Azizan A, Kim JK. Transparent, electrically conductive, and flexible films made from multiwalled carbon nanotube/epoxy composites. Composites B, 43, 2973 (2012). http://dx.doi.org/10.1016/j.compositesb.2012.05.048.

[46] Gojny FH, Wichmann MHG, Fiedler B, Schulte K. Influence of different carbon nanotubes on the mechanical properties of epoxy matrix composites: a comparative study. Compos Sci Technol, 65, 2300 (2005). http://dx.doi.org/10.1016/j.compscitech.2005.04.021.

[47] Prolongo SG, Gude MR, Urena A. Improving the flexural and thermomechanical properties of amino-functionalized carbon nanotube/epoxy composites by using a pre-curing treatment. Compos Sci Technol, 71, 765 (2011). http://dx.doi.org/10.1016/j.compsci- tech.2011.01.028.

[48] Cividanes LS, Brunelli DD, Antunes EF, Corat EJ, Sakane KK, Thim GP. Cure study of epoxy resin reinforced with multiwalled carbon nanotubes by Raman and luminescence spectroscopy. J Appl Polym Sci, 127, 544 (2013). http://dx.doi.org/10.1002/ app. 37815 .

[49] Kim MT, Rhee KY, Park SJ, Hui D. Effects of silane-modified carbon nanotubes on flexural and fracture behaviors of carbon nanotube-modified epoxy/basalt composites. Composites B, 43, 2298 (2012). http://dx.doi.org/10.1016/j.compositesb.2011.12.007.

[50] Zehua Q, Guojian W. A comparative study on the properties of the different amino-functionalized multiwall carbon nanotubes reinforced epoxy resin composites. J Appl Polym Sci, 124, 403 (2012). http://dx.doi.org/10.1002/app.35105.

[51] Farahani RD, Dalir H, Le Borgne V, Gautier LA, El Khakani MA, Levesque M, Therriault D. Reinforcing epoxy nanocomposites with functionalized carbon nanotubes via biotin-streptavidin interactions. Compos Sci Technol, 72, 1387 (2012). http://dx.doi. org/10.1016/j.compscitech.2012.05.010.

[52] Kwon Y, Yim BS, Kim JM, Kim J. Dispersion, hybrid interconnection and heat dissipation properties of functionalized carbon nanotubes in epoxy composites for electrically conductive adhesives (ECAs). Microelectron Reliab, 51, 812 (2011). http://dx.doi. org/10.1016/j.microrel.2010.11.005.

[53] Xu J, Yao P, Jiang Z, Liu H, Li X, Liu L, Li M, Zheng Y. Preparation, morphology, and properties of conducting polyaniline-grafted multiwalled carbon nanotubes/epoxy composites. J Appl Polym Sci, 125, E334 (2012). http://dx.doi.org/10.1002/app.35677.

[54] Guo P, Chen X, Gao X, Song H, Shen H. Fabrication and mechanical properties of well-dispersed multiwalled carbon nanotubes/ epoxy composites. Compos Sci Technol, 67, 3331 (2007). http:// dx.doi.org/10.1016/j.compscitech.2007.03.026.

[55] Kim KS, Park SJ. Influence of surface treatment of multi-walled carbon nanotubes on interfacial interaction of nanocomposites. Carbon Lett, 11, 102 (2010). http://dx.doi.org/10.5714/CL.2010. 11.2.102.

[56] Martin CA, Sandler JKW, Shaffer MSP, Schwarz MK, Bauhofer W, Schulte K, Windle AH. Formation of percolating networks in multi-wall carbon-nanotube-epoxy composites. Compos Sci Technol, 64, 2309 (2004). http://dx.doi.org/10.1016/j.compscitech. 2004.01.025.

[57] Liu L, Etika KC, Liao KS, Hess LA, Bergbreiter DE, Grunlan JC. Comparison of covalently and noncovalently functionalized carbon nanotubes in epoxy. Macromol Rapid Commun, 30, 627 (2009). http://dx.doi.org/10.1002/marc.200800778.

[58] Bai JB, Allaoui A. Effect of the length and the aggregate size of MWNTs on the improvement efficiency of the mechanical and electrical properties of nanocomposites - experimental investigation. Composites A, 34, 689 (2003). http://dx.doi.org/10.1016/ S1359-835X(03)00140-4. 